Article

\title{
Measurement of the Spatial Complexity and Its Influencing Factors of Agricultural Green Development in China
}

\author{
Hongpeng Guo $\mathbb{D}^{\mathbb{D}}$, Shuang $X \mathrm{u}^{\mathbb{D}}$ and Chulin Pan * $\mathbb{D}$ \\ Department of Agricultural and Forestry Economic Management, College of Biological and Agricultural \\ Engineering, Jilin University, 5988 Renmin Street, Changchun 130022, China; ghp@jlu.edu.cn (H.G.); \\ xushuang_jlu@163.com (S.X.) \\ * Correspondence: pancl@jlu.edu.cn
}

Received: 17 October 2020; Accepted: 5 November 2020; Published: 7 November 2020

check for updates

\begin{abstract}
The article focuses on the spatial complexity of agricultural green development (AGD) in different regions. The article first constructs an evaluation index system for the level of AGD from four dimensions: Social development, economic benefits, resource input, and ecological environment. Then, the article uses an improved entropy weight method to evaluate the level of AGD with panel data of 31 provinces in China from 2007 to 2018. Finally, on the basis of Moran Index and the Spatial Durbin Model, the article analyzes the spatial heterogeneity of the factors that affect the green development of agriculture in China. The results show that: (1) From 2007 to 2018, the overall level of AGD shows a fluctuating upward trend in China, and there are differences among provinces. The level of AGD in the three major regions presents the characteristics of Eastern $>$ Central > Western; (2) China's provincial AGD level has an obvious positive autocorrelation in spatial distribution, showing significant spatial agglomeration characteristics in space; (3) the four factors of urbanization level, agricultural mechanization level, scientific and technological R\&D investment, and arable area, have different effects on the level of AGD in three major regions. This study provides a reference for understanding the status of China's agricultural green development level and policy recommendations on how to improve the level of agricultural green development. The results imply that some effective policy measures, such as prompting the integrated development of the three major industries and optimizing the industrial structure, should be taken to coordinate "green" with "development" from national and regional perspectives.
\end{abstract}

Keywords: agricultural green development; entropy weight method; spatial heterogeneity; spatial spillover effect; China

\section{Introduction}

Agriculture plays a central role in sustainable development, which determines the relationship between the global economy, society, and the natural world [1]. Since China implemented the reform and opening policy in 1978, China's agriculture has developed rapidly, producing considerable economic benefits and meeting the growing food demand of people [2,3]. China has done remarkable work in feeding $22 \%$ of the world's population with only $9 \%$ of the world's arable land, making an important contribution to international food security [4]. At the same time, China has also paid a huge environmental price. Environmental problems such as water eutrophication, soil acidification, air pollution, the reduction of biodiversity, etc., have become increasingly prominent, which greatly hinders the green and sustainable development of agriculture [5-7]. Therefore, China needs to coordinate the relationship between agricultural development and environmental protection urgently and promote the green transformation of agriculture. 
In recent years, China has realized the importance of agricultural green development. Different ways have been adopted in different provinces in the process of agricultural green development, which have achieved varying degrees of effectiveness. However, how to realize the sustainable utilization of resources and sustainable development of agriculture while protecting the environment is still an urgent problem to be solved.

Agriculture Green Development is the future development direction of agriculture for China and the world [8-10]. In order to achieve green development in agriculture, it is necessary to make a quantitative evaluation of the current agricultural development level. In previous studies, in order to evaluate the sustainable agricultural development, many scholars have constructed different evaluation index systems for sustainable agricultural development around three dimensions, including society, economy, and ecology, evaluating the sustainable development of agriculture from the perspectives of farms, regions, and countries [11-16]. In recent years, under the background of green transformation of agriculture, scholars have studied from different perspectives on the construction of evaluation index system and evaluation methods of agricultural green development. For instance, Wei et al. selected 14 indicators from four dimensions of resource conservation, ecological conservation, environmental friendliness, and quality efficiency to construct China's agricultural green development index, then evaluating the level of agricultural green development in China [17]. Gong et al. selected 10 indicators from three dimensions of low-carbon economy, economic growth, and safe supply to construct a development index to evaluate the level of agricultural green development [18]. More scholars have used principal component analysis [19], entropy weight method [20-22], or analytic hierarchy process [23] to evaluate the level of agricultural green development in different provinces of China.

The overall objective of Agriculture Green Development is to coordinate "green" with "development" to realize the transformation of current agriculture with high resource consumption and high environmental costs into a green agriculture and countryside with high productivity, high resource use efficiency, and low environmental impact [10]. However, the resource and environment cost of agricultural production in China is too high. Irrational fertilization leads to serious acidification of croplands, which poses a threat to agricultural production and hinders China's green development of agriculture seriously $[5,24,25]$. In areas with scarce water resources, the quality and safety of agricultural products cannot be guaranteed, which will also hinder the green development of agriculture [26]. $\mathrm{Tu}$ et al. pointed out that the green development of agriculture is not only reflected in the low agricultural non-point source pollution, but also in the high efficiency of agricultural production [27]. Inconsistent agricultural development conditions, different ecological environments, and different resource endowments in various regions have an impact on agricultural production and the level of agricultural development $[28,29]$. In addition, changes in institutions and policies, the level of urbanization, and the level of science and technology also have an impact on agricultural production efficiency [30]. Among many influencing factors, technological progress has been regarded as the main driving factor of agricultural production [31]. Meanwhile, the green development of agriculture puts forward higher requirements for technological progress, which requires the integration of multiple disciplines and technological innovation to realize the green development of agriculture [32,33].

Through reviewing literatures, since the concept of agricultural green development is relatively new, most studies mainly focus on two aspects: The first is the construction and level measurement of the evaluation index system of agricultural green development, and the second is the driving or restrictive factors that affect agricultural green development. The research on the spatial characteristics of agricultural green development and its influencing factors is still blank. Therefore, this article first evaluates the status of agricultural green development level in China through improved entropy weight method to measure the level of agricultural green development. Then, in order to study the spatial correlation and heterogeneity of agricultural green development in China, the article conducted an empirical analysis on the influencing factors of agricultural green development with panel data from 31 provinces in China. This study provides data support and empirical basis for the proposal and formulation of agricultural green development policy in different regions of China. 


\section{Materials and Methods}

\subsection{Materials}

\subsubsection{Construction of Evaluation Index System for Agricultural Green Development Level}

According to the definition of the level of agricultural green development and the research of other scholars, this article selects 16 indicators from four perspectives, including social development, economic benefits, resource input, and ecological environment to construct an evaluation index system for the level of agricultural green development in China, as shown in Table 1. All data are derived from the China Statistical Yearbook, China Rural Statistical Yearbook, China Environment Statistical Yearbook, and Provincial Statistical Yearbook from 2008 to 2019.

Table 1. Evaluation index system of agricultural green development level.

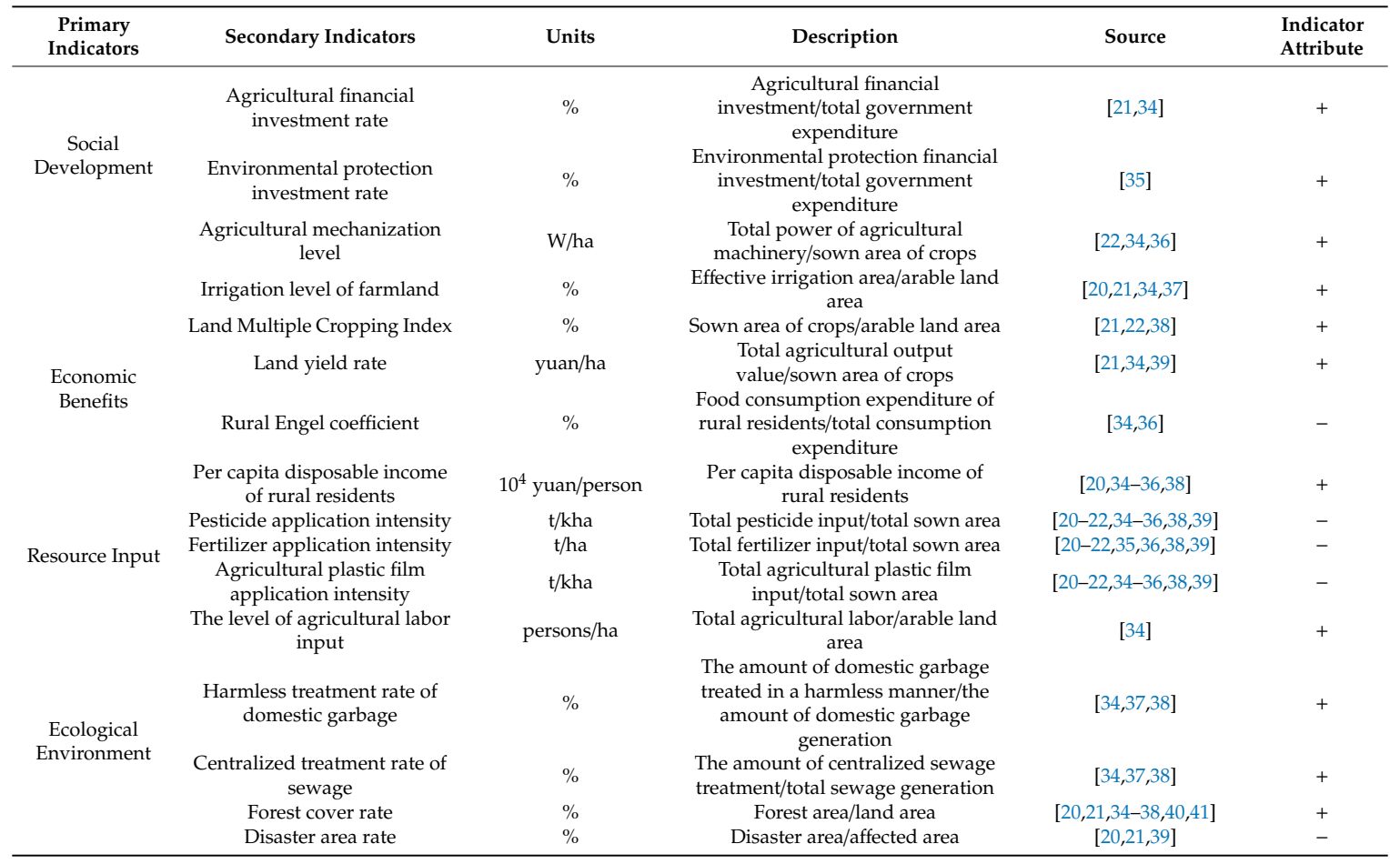

\subsubsection{Influencing Factors of Agricultural Green Development}

This paper used the level of agricultural green development in each province as the explained variable, and $u r b$, mech, $r n d$, and land as the explanatory variables to analyze the impact of each variable on the green development of agriculture. The specific meaning is as follows:

$u r b$ : A variable that represents the level of urbanization, which is reflected by the proportion of urban population in the total population. On the one hand, urbanization can gather social resources in a certain space and accelerate the transformation and upgrading of industrial structure. On the other hand, the improvement of urbanization level can increase the emission of environmental pollution and inhibit the green development of agriculture [42,43].

mech: A variable that represents the level of mechanization, which is reflected by the total power of agricultural machinery. The improvement of the level of mechanization is conducive to improving the efficiency of agricultural production and has a positive impact on the green development of agriculture [27].

rnd: A variable that represents the investment in scientific and technological research and development, which is reflected by the scientific and technological expenditure. The investment 
in scientific research and development can promote technological progress, improve agricultural production efficiency, and promote the green development of agriculture [30,44].

land: A variable that represents the area of arable land, which is reflected by the arable land area. Arable land is an indispensable element in agricultural production. For one thing, arable land area represents the resource endowment of a certain area, which can increase crop yields and promote the green development of agriculture. For another, the area of arable land decreases year by year while the utilization and output rate of arable land are increased, which has a positive impact on the green development of agriculture.

\subsection{Entropy Weight Method}

In the application of comprehensive evaluation methods, there are multiple evaluation methods, which can be divided into subjective weighting method and objective weighting method when determining the weight of each index. Subjective weighting methods tend to rely on subjective judgments and lacks certain objectivity, which makes the evaluation result subjectively random. The objective method uses the value of indicators to calculate the weight without considering human factors. Entropy weight method determines each index's weight on the basis of amount of information. Among the objective methods, entropy weight method has been widely used in many fields, which will make the evaluation more accurate when dealing with large amounts of data.

Therefore, we selected the entropy weight method of objective weighting methods to determine the weight of various indicators through information entropy, and then made a comprehensive evaluation of the level of agricultural green development in China. Data selected were panel data containing both time series and cross-section. In order to guarantee the comparability among different years, time variable was introduced to improve the entropy weight method. The formula of improved entropy weight method is expressed as Equations (1)-(8) [45].

Step 1 Construct the original index matrix data: assume there are $h$ years, $n$ provinces, and $m$ indicators, then the original index matrix is $X=\left\{x_{\lambda i j}\right\}_{h * n * m}(1 \leq \lambda \leq h, 1 \leq i \leq n, 1 \leq j \leq m)$, where $x_{\lambda i j}$ represents the index $j$ of province $n$ in year $h$. In this article, $h, n$ and $m$ are 12,31, and 16 .

Step 2 Range standardize and dimensionless processing of each indicator in the index system, as is shown in Equations (1) and (2).

Standardization of positive indicators:

$$
Z_{\lambda i j}=\frac{x_{\lambda i j}-x_{\min }}{x_{\max }-x_{\min }}
$$

Standardization of negative indicators:

$$
Z_{\lambda i j}=\frac{x_{\max }-x_{\lambda i j}}{x_{\max }-x_{\min }}
$$

Step 3 Normalization of indicators, as is shown in Equation (3):

$$
P_{\lambda i j}=\frac{Z_{\lambda i j}}{\sum_{\lambda=1}^{h} \sum_{i=1}^{n} Z_{\lambda i j}}
$$

Step 4 Calculate the entropy of each indicator, as is shown in Equations (4) and (5):

$$
E_{j}=-k \sum_{\lambda=1}^{h} \sum_{i=1}^{n} P_{\lambda i j} \ln P_{\lambda i j}
$$




$$
k=\frac{1}{\ln (h \times n)}
$$

Step 5 Calculate the redundancy of the entropy values of each indicator, as is shown in Equation (6):

$$
D_{j}=1-E_{j}
$$

Step 6 Calculate the weight of each indicator, as is shown in Equation (7):

$$
W_{j}=\frac{D_{j}}{\sum_{j=1}^{m} D_{j}}
$$

Step 7 Calculate the level of agricultural green development in each province in each year, as is shown in Equation (8).

$$
C_{\lambda i}=Z_{\lambda i j} \times W_{j}
$$

\subsection{The Spatial Autocorrelation Analysis Method}

\subsubsection{Global Spatial Autocorrelation}

Before studying the spillover effects of agricultural green development level in China, it is necessary to test whether there exits statistical spatial correlation among the provincial agricultural green development level. It is common in the literature to measure the global spatial autocorrelation with Moran's I index. The formula of Moran's I is calculated in Equation (9) [46].

$$
\text { Moran's } I=\frac{n}{\sum_{i=1}^{n}\left(x_{i}-\bar{x}\right)^{2}} \frac{\sum_{i=1}^{n} \sum_{j=1}^{n} w_{i j}\left(x_{i}-\bar{x}\right)\left(x_{j}-\bar{x}\right)}{\sum_{i=1}^{n} \sum_{j=1}^{n} w_{i j}}
$$

where $x_{i}$ denotes the observed value of the agricultural green development level in province $i ; x_{j}$ denotes the observed value of the agricultural green development level in province $j ; \bar{x}$ denotes the mean of observed values of the agricultural green development level; $n$ denotes the total provincial number; $w_{i j}$ denotes the spatial weight matrix. We used 0-1 adjacent space weight matrix as the spatial weight matrix in this article. The definition is shown in Equation (10).

$$
w_{i j}=\left\{\begin{array}{l}
1, \text { province } i \text { adjacent to province } j \\
0, \text { otherwise }
\end{array}, i=1,2, \cdots, n ; j=1,2, \cdots, n\right.
$$

Moran's I index ranges from -1 to 1 . The Moran's I index shows a positive spatial autocorrelation if it is between 0 and 1 , which represents that the "high value" is adjacent to the "high value", and the "low value" is adjacent to the "low value". The Moran's I index shows a negative spatial autocorrelation if it is between -1 and 0 , which represents that the "high value" is adjacent to the "low value". There is no spatial autocorrelation if the Moran's I index is 0 [47].

\subsubsection{Local Spatial Autocorrelation}

The meaning of the local Moran index is similar to that of the global Moran index, which is expressed as Equation (11). If Moran's $I_{i}>0$, it means that the "high(low) value" in region $i$ is 
surrounded by the "high(low) value". Otherwise, if Moran's $I_{i}<0$, it means that the "high(low) value" in region $i$ is surrounded by the "low(high) value" [47].

$$
\text { Moran's } I_{i}=\frac{n^{2}}{\sum_{i=1}^{n}\left(x_{i}-\bar{x}\right)^{2}} \frac{\left(x_{i}-\bar{x}\right) \sum_{i=1}^{n} \sum_{j=1}^{n} w_{i j}\left(x_{j}-\bar{x}\right)}{\sum_{i=1}^{n} \sum_{j=1}^{n} w_{i j}}
$$

\subsection{Spatial Panel Data Model}

Spatial econometric models mainly include Spatial Durbin Model (SDM), Spatial Autoregressive Model (SAR), and Spatial Error Model (SEM). The SDM model is more general, which is a general model including SAR model and SEM model. The model is expressed as Equation (12) [44].

$$
Y=\rho W Y+X \beta+\theta W X+\varepsilon
$$

where $\rho$ represents the spatial autocorrelation coefficient, $W$ represents the spatial weight matrix, $X$ represents the explanatory variables, $W X$ represents the spatial lag of explanatory variables, $\beta$ represents the regression coefficient of the explanatory variables, and $\varepsilon$ represents the random error term.

When $\theta=0$, the SDM model will be simplified to the SAR model. The model is expressed as Equation (13).

$$
Y=\rho W Y+X \beta+\varepsilon
$$

When $\theta+\rho \beta=0$, the SDM model will be simplified to the SEM model. The model is expressed as Equations (14) and (15).

$$
\begin{gathered}
Y=X \beta+u \\
u=\lambda W u+\varepsilon
\end{gathered}
$$

\section{Empirical Results and Discussion}

\subsection{Calculation of Agricultural Green Development Level}

According to the basic principle of entropy weight method, the article calculated the index weight of each index step by step, and then calculated the level of agricultural green development of 31 provinces (cities and municipalities) from 2007 to 2018 through weighted calculation. The results are shown in Table 2.

It can be seen from Table 2 that from 2007 to 2018, the overall level of agriculture green development in China shows a slow upward trend. The average national level of agricultural green development fluctuated from 0.429 to 0.468 , with an average annual growth rate of $0.76 \%$. Provincial level of the agricultural green development shows an upward trend, but there exist differences among provinces. Among the top 10 provinces in terms of average level are 8 provinces in the eastern region, while among the bottom 10 provinces in terms of average level are 7 provinces in the western region. It can be seen that the provinces with a higher level of agricultural green development in China are concentrated in the eastern area, and the provinces with a lower level of development are concentrated in the western region. The three major regions have significant regional differences in the level of agricultural green development, showing the spatial characteristics of Eastern $>$ Central $>$ Western on the whole. In addition, the range of provincial agricultural green development level decreased from 0.341 to 0.274 , indicating that the gap of agricultural green development level among provinces in China is decreasing. 
Table 2. The level of agricultural green development (AGD) evaluation results in China during 2007-2018.

\begin{tabular}{|c|c|c|c|c|c|c|c|c|c|c|c|c|c|c|}
\hline \multirow{2}{*}{ Province } & \multicolumn{12}{|c|}{ Year } & \multirow{2}{*}{ Level } & \multirow{2}{*}{ Ranking } \\
\hline & 2007 & 2008 & 2009 & 2010 & 2011 & 2012 & 2013 & 2014 & 2015 & 2016 & 2017 & 2018 & & \\
\hline Zhejiang & 0.630 & 0.635 & 0.606 & 0.625 & 0.615 & 0.626 & 0.649 & 0.622 & 0.610 & 0.631 & 0.602 & 0.589 & 0.620 & 1 \\
\hline Fuiian & 0.564 & 0.599 & 0.581 & 0.564 & 0.594 & 0.607 & 0.637 & 0.622 & 0.616 & 0.648 & 0.594 & 0.596 & 0.602 & 2 \\
\hline Beijing & 0.611 & 0.600 & 0.629 & 0.599 & 0.636 & 0.617 & 0.609 & 0.584 & 0.529 & 0.567 & 0.585 & 0.581 & 0.595 & 3 \\
\hline Guangdong & 0.524 & 0.551 & 0.578 & 0.602 & 0.604 & 0.609 & 0.623 & 0.580 & 0.554 & 0.594 & 0.563 & 0.612 & 0.583 & 4 \\
\hline Shanghai & 0.533 & 0.561 & 0.590 & 0.593 & 0.546 & 0.589 & 0.607 & 0.596 & 0.558 & 0.560 & 0.605 & 0.555 & 0.574 & 5 \\
\hline Jiangsu & 0.508 & 0.498 & 0.522 & 0.501 & 0.528 & 0.543 & 0.569 & 0.555 & 0.545 & 0.570 & 0.521 & 0.543 & 0.534 & 7 \\
\hline Hebei & 0.463 & 0.460 & 0.466 & 0.475 & 0.480 & 0.499 & 0.526 & 0.513 & 0.515 & 0.512 & 0.515 & 0.532 & 0.496 & 9 \\
\hline Shandong & 0.493 & 0.496 & 0.481 & 0.477 & 0.504 & 0.517 & 0.526 & 0.492 & 0.481 & 0.478 & 0.492 & 0.486 & 0.494 & 10 \\
\hline Tianjin & 0.452 & 0.419 & 0.381 & 0.424 & 0.454 & 0.448 & 0.499 & 0.431 & 0.480 & 0.422 & 0.490 & 0.416 & 0.443 & 17 \\
\hline Liaoning & 0.396 & 0.391 & 0.362 & 0.346 & 0.380 & 0.378 & 0.395 & 0.387 & 0.404 & 0.413 & 0.412 & 0.412 & 0.390 & 25 \\
\hline Eastern & 0.506 & 0.514 & 0.511 & 0.513 & 0.527 & 0.537 & 0.555 & 0.531 & 0.521 & 0.537 & 0.534 & 0.531 & 0.526 & \\
\hline Hunan & 0.510 & 0.518 & 0.540 & 0.544 & 0.545 & 0.574 & 0.597 & 0.596 & 0.587 & 0.611 & 0.581 & 0.585 & 0.566 & 6 \\
\hline Jiangxi & 0.512 & 0.540 & 0.526 & 0.512 & 0.498 & 0.519 & 0.492 & 0.510 & 0.514 & 0.547 & 0.537 & 0.536 & 0.520 & 8 \\
\hline Henan & 0.487 & 0.470 & 0.478 & 0.464 & 0.472 & 0.496 & 0.495 & 0.469 & 0.481 & 0.484 & 0.492 & 0.500 & 0.482 & 11 \\
\hline Hubei & 0.408 & 0.418 & 0.444 & 0.465 & 0.465 & 0.472 & 0.510 & 0.489 & 0.475 & 0.480 & 0.485 & 0.510 & 0.468 & 12 \\
\hline Anhui & 0.444 & 0.436 & 0.447 & 0.422 & 0.457 & 0.448 & 0.505 & 0.474 & 0.458 & 0.487 & 0.475 & 0.493 & 0.462 & 13 \\
\hline Heilongjiang & 0.360 & 0.373 & 0.369 & 0.361 & 0.370 & 0.425 & 0.400 & 0.412 & 0.419 & 0.406 & 0.455 & 0.438 & 0.399 & 21 \\
\hline Jilin & 0.336 & 0.392 & 0.362 & 0.350 & 0.403 & 0.420 & 0.421 & 0.406 & 0.392 & 0.379 & 0.351 & 0.383 & 0.383 & 28 \\
\hline Central & 0.424 & 0.438 & 0.440 & 0.432 & 0.443 & 0.466 & 0.479 & 0.468 & 0.462 & 0.470 & 0.467 & 0.480 & 0.456 & \\
\hline Guangxi & 0.409 & 0.426 & 0.443 & 0.445 & 0.445 & 0.456 & 0.498 & 0.476 & 0.478 & 0.485 & 0.481 & 0.473 & 0.460 & 15 \\
\hline Sichuan & 0.463 & 0.452 & 0.452 & 0.432 & 0.434 & 0.469 & 0.493 & 0.467 & 0.460 & 0.446 & 0.451 & 0.461 & 0.457 & 16 \\
\hline Chongqing & 0.427 & 0.420 & 0.428 & 0.451 & 0.439 & 0.453 & 0.472 & 0.432 & 0.431 & 0.438 & 0.443 & 0.442 & 0.440 & 18 \\
\hline Shaanxi & 0.390 & 0.421 & 0.412 & 0.415 & 0.445 & 0.445 & 0.441 & 0.427 & 0.423 & 0.419 & 0.433 & 0.428 & 0.425 & 19 \\
\hline Yunnan & 0.386 & 0.394 & 0.410 & 0.415 & 0.401 & 0.434 & 0.427 & 0.418 & 0.406 & 0.443 & 0.414 & 0.411 & 0.413 & 20 \\
\hline Guizhou & 0.370 & 0.352 & 0.376 & 0.392 & 0.346 & 0.413 & 0.394 & 0.417 & 0.421 & 0.430 & 0.433 & 0.444 & 0.399 & 22 \\
\hline Qinghai & 0.396 & 0.397 & 0.404 & 0.389 & 0.420 & 0.396 & 0.443 & 0.412 & 0.391 & 0.387 & 0.368 & 0.359 & 0.397 & 23 \\
\hline Xinjiang & 0.397 & 0.387 & 0.356 & 0.396 & 0.378 & 0.412 & 0.409 & 0.409 & 0.392 & 0.399 & 0.380 & 0.400 & 0.393 & 24 \\
\hline Ningxia & 0.350 & 0.395 & 0.355 & 0.405 & 0.391 & 0.394 & 0.403 & 0.397 & 0.363 & 0.359 & 0.394 & 0.427 & 0.386 & 26 \\
\hline Inner Mongolia & 0.372 & 0.421 & 0.360 & 0.360 & 0.367 & 0.374 & 0.390 & 0.390 & 0.388 & 0.380 & 0.392 & 0.412 & 0.384 & 27 \\
\hline Tibet & 0.392 & 0.355 & 0.345 & 0.348 & 0.384 & 0.371 & 0.352 & 0.337 & 0.381 & 0.330 & 0.333 & 0.368 & 0.358 & 30 \\
\hline Gansu & 0.289 & 0.296 & 0.309 & 0.314 & 0.290 & 0.310 & 0.305 & 0.296 & 0.295 & 0.277 & 0.331 & 0.338 & 0.304 & 31 \\
\hline Western & 0.387 & 0.393 & 0.387 & 0.397 & 0.395 & 0.411 & 0.419 & 0.407 & 0.402 & 0.399 & 0.404 & 0.414 & 0.401 & \\
\hline Nation & 0.429 & 0.440 & 0.436 & 0.434 & 0.446 & 0.463 & 0.474 & 0.460 & 0.456 & 0.461 & 0.461 & 0.468 & 0.452 & \\
\hline
\end{tabular}




\subsection{Spatial Correlation Analysis}

\subsubsection{Global Autocorrelation Test}

The results of the Moran's I index are shown in Table 3. It shows that the Moran's I index of provincial agricultural green development level in China is positive at the significance of $5 \%$ from 2007 to 2018. It indicates that provincial agricultural green development has an obvious positive autocorrelation in the spatial distribution. The level of provincial agricultural green development presents a spatial agglomeration effect. A positive spatial correlation means that the characteristics of adjacent provinces are similar, that is, provinces with higher level tend to be close to those with higher level, or provinces with lower level tend to be relatively close to those with lower level. Therefore, there is a spatial correlation between the provincial level of agricultural green development in China on the whole, which means that the level of agricultural green development shows significant spatial agglomeration characteristics in space.

Table 3. Global Moran's I of AGD level during 2007-2018.

\begin{tabular}{cccccc}
\hline Year & $\mathbf{I}$ & $\mathbf{E}$ (I) & Sd (I) & $\mathbf{Z}$ & $p$-Value \\
\hline 2007 & 0.501 & -0.033 & 0.107 & 4.422 & 0.000 \\
2008 & 0.482 & -0.033 & 0.107 & 4.223 & 0.000 \\
2009 & 0.505 & -0.033 & 0.108 & 4.529 & 0.000 \\
2010 & 0.536 & -0.033 & 0.107 & 4.686 & 0.000 \\
2011 & 0.504 & -0.033 & 0.107 & 4.479 & 0.000 \\
2012 & 0.531 & -0.033 & 0.107 & 4.689 & 0.000 \\
2013 & 0.553 & -0.033 & 0.107 & 4.760 & 0.000 \\
2014 & 0.544 & -0.033 & 0.107 & 4.823 & 0.000 \\
2015 & 0.610 & -0.033 & 0.107 & 5.407 & 0.000 \\
2016 & 0.642 & -0.033 & 0.107 & 5.735 & 0.000 \\
2017 & 0.636 & -0.033 & 0.108 & 5.456 & 0.000 \\
2018 & 0.612 & -0.033 & 0.108 & 5.371 & 0.000 \\
\hline
\end{tabular}

\subsubsection{Local Correlation Test}

In order to further test the spatial relationship of agricultural green development in China and investigate the distribution characteristics of agricultural green development in local areas, the article draws the local Moran index scatter plot of some years $(2007,2011,2015,2018)$ based on the 0-1 adjacent spatial weight matrix, as is shown in Figure 1a-d. The presentation of Moran scatter plot is to divide the space into four quadrant units, and different quadrant units represent the relationship between the local spatial unit and its adjacent spatial unit. Specifically, the first quadrant is a high-high $(\mathrm{H}-\mathrm{H})$ agglomeration area, which means that the region with a high level is surrounded by regions with high level. The second quadrant is a low-high $(\mathrm{L}-\mathrm{H})$ agglomeration area, which means that the region with a low level is surrounded by regions with high level. The third quadrant is a low-low (L-L) agglomeration area, which means that the regions with a low level is surrounded by regions with low level. The fourth quadrant is a high-low (H-L) agglomeration area, which means that the region with a high level is surrounded by regions with low level. 


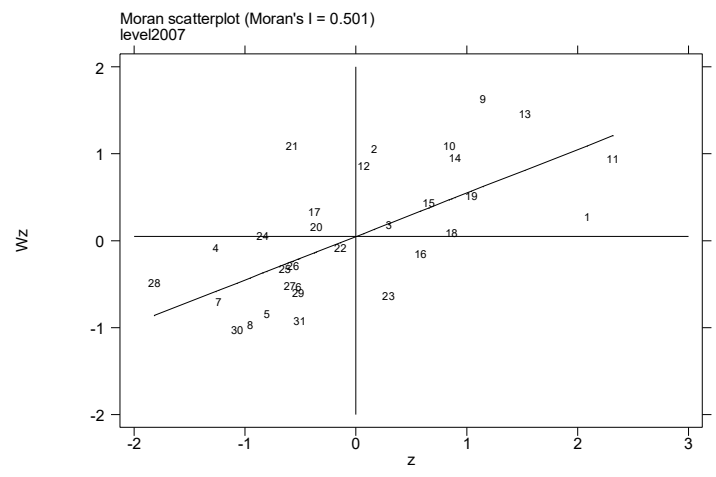

(a) 2007

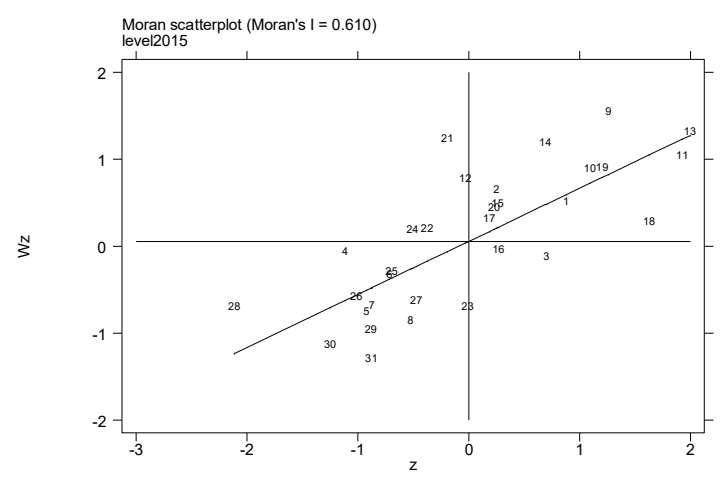

(c) 2015

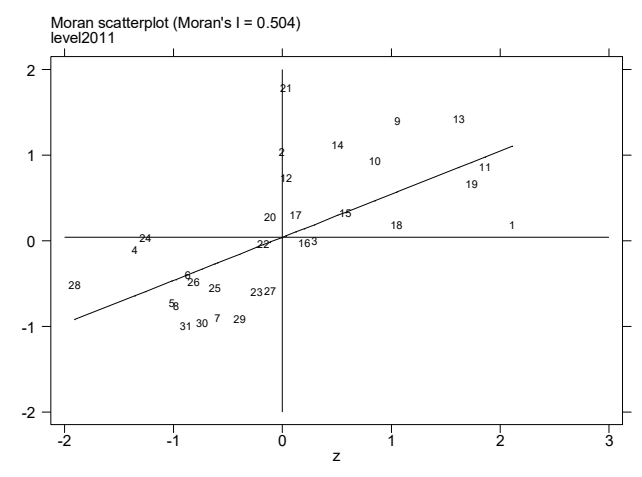

(b) 2011

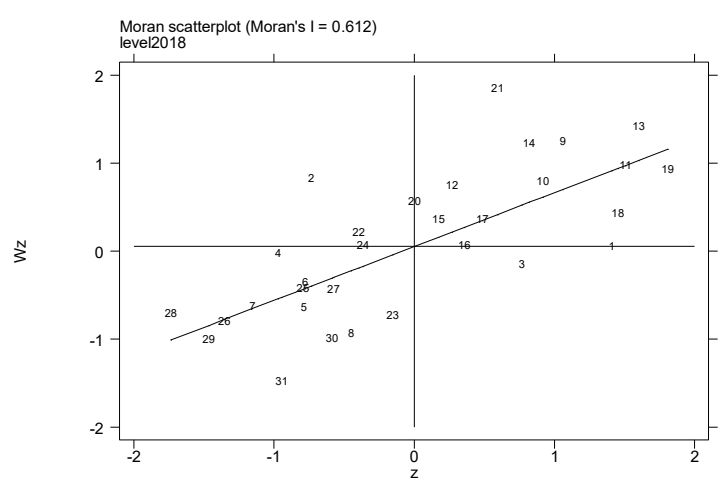

(d) 2018

Figure 1. Local Moran index scatter plot of AGD level.

In order to understand the agglomeration or dispersion of provinces more intuitively, the data of each quadrant were summarized and presented in the form shown in Table 4 . From the perspective of time dynamics, the level of green agricultural development in various provinces has changed, but in the selected four years, most of the provinces are located in the $\mathrm{H}-\mathrm{H}$ and L-L agglomeration areas. From a long-term perspective, the provinces located in each quadrant have relatively little change. Provinces located in the $\mathrm{H}-\mathrm{H}$ agglomeration area for a long time are mostly provinces in the eastern coastal area, while the provinces located in the L-L agglomeration area are mostly provinces in the western region. It indicates that agricultural green development in China exists as a local spatial correlation, and the level of agricultural green development in different provinces exists spatially heterogeneously.

Table 4. Local Moran index province distribution of AGD level.

\begin{tabular}{|c|c|c|c|c|}
\hline & 2007 & 2011 & 2015 & 2018 \\
\hline $\begin{array}{l}\mathrm{H}-\mathrm{H} \text { agglomeration } \\
\text { (the first quadrant) }\end{array}$ & $\begin{array}{c}\text { Beijing, Tianjin, } \\
\text { Hebei, Shanghai, } \\
\text { Jiangsu, Zhejiang, } \\
\text { Anhui, Fujian, } \\
\text { Jiangxi, Shandong, } \\
\text { Hunan, } \\
\text { Guangdong }\end{array}$ & $\begin{array}{l}\text { Beijing, Shanghai, } \\
\text { Jiangsu, Zhejiang, } \\
\text { Anhui, Fujian, } \\
\text { Jiangxi, Shandong, } \\
\text { Hubei, Hunan, } \\
\text { Guangdong, } \\
\text { Hainan }\end{array}$ & $\begin{array}{l}\text { Beijing, Tianjin, } \\
\text { Shanghai, Jiangsu, } \\
\text { Zhejiang, Fujian, } \\
\text { Jiangxi, Shandong, } \\
\text { Hubei, Hunan, } \\
\text { Guangdong, } \\
\text { Guangxi }\end{array}$ & $\begin{array}{c}\text { Beijing, Shanghai, } \\
\text { Jiangsu, Zhejiang, } \\
\text { Anhui, Fujian, } \\
\text { Jiangxi, Shandong, } \\
\text { Henan, Hubei, } \\
\text { Hunan, } \\
\text { Guangdong, } \\
\text { Guangxi, Hainan }\end{array}$ \\
\hline $\begin{array}{l}\text { L-H agglomeration } \\
\text { (the second } \\
\text { quadrant) }\end{array}$ & $\begin{array}{l}\text { Hubei, Guangxi, } \\
\text { Hainan, Guizhou }\end{array}$ & Tianjin, Guangxi & $\begin{array}{l}\text { Anhui, Hainan, } \\
\text { Chongqing, } \\
\text { Guizhou }\end{array}$ & $\begin{array}{c}\text { Tianjin, Chongqing, } \\
\text { Guizhou }\end{array}$ \\
\hline
\end{tabular}


Table 4. Cont.

\begin{tabular}{|c|c|c|c|c|}
\hline & 2007 & 2011 & 2015 & 2018 \\
\hline $\begin{array}{l}\text { L-L agglomeration } \\
\text { the third quadrant) }\end{array}$ & $\begin{array}{c}\text { Shanxi, Inner } \\
\text { Mongolia, } \\
\text { Liaoning, Jilin, } \\
\text { Heilongjiang, } \\
\text { Chongqing, } \\
\text { Yunnan, Tibet, } \\
\text { Shaanxi, Gansu, } \\
\text { Qinghai, Ningxia, } \\
\text { Xinjiang }\end{array}$ & $\begin{array}{c}\text { Shanxi, Inner } \\
\text { Mongolia, } \\
\text { Liaoning, Jilin, } \\
\text { Heilongjiang, } \\
\text { Chongqing, } \\
\text { Sichuan, Guizhou, } \\
\text { Yunnan, Tibet, } \\
\text { Shaanxi, Gansu, } \\
\text { Qinghai, Ningxia, } \\
\text { Xinjiang }\end{array}$ & $\begin{array}{l}\text { Shanxi, Inner } \\
\text { Mongolia, } \\
\text { Liaoning, Jilin, } \\
\text { Heilongjiang, } \\
\text { Sichuan, Yunnan, } \\
\text { Tibet, Shaanxi, } \\
\text { Gansu, Qinghai, } \\
\text { Ningxia, Xinjiang }\end{array}$ & $\begin{array}{c}\text { Shanxi, Inner } \\
\text { Mongolia, } \\
\text { Liaoning, Jilin, } \\
\text { Heilongjiang, } \\
\text { Sichuan, Yunnan, } \\
\text { Tibet, Shaanxi, } \\
\text { Gansu, Qinghai, } \\
\text { Ningxia, Xinjiang }\end{array}$ \\
\hline $\begin{array}{l}\text { H-L agglomeration } \\
\text { (the fourth } \\
\text { quadrant) }\end{array}$ & Henan, Sichuan & Hebei, Henan & Hebei, Henan & Hebei \\
\hline
\end{tabular}

\subsection{Spatial Econometric Analysis}

\subsubsection{Model Test and Selection}

Before the spatial econometric regression, it is necessary to analyze the panel data with the ordinary least squares (OLS) model. First, we used F test to compare the fixed effect model with the mixed effect model without considering spatial correlation, and the result showed that the fixed effect model was better than the mixed effect model. Then, we used the Breusch and Pagan (B\&P) test to compare the random effect model and the mixed effect model, and the result showed that the random effect model was better than the mixed effect model. Finally, we used Hausman test to compare the random effect model and the fixed effect model, and the result showed that the fixed effect model was better than the random effect model. The test results are shown in Table 5. Through the above three tests, we found that the fixed effect model is more suitable. Therefore, the fixed effect model was used for further spatial econometric model selection to analyze the influencing factors of agricultural green development level in China.

Table 5. Panel data related effect diagnosis results.

\begin{tabular}{cccc}
\hline Test & F & Chi2 & $p$-Value \\
\hline F test & 56.10 & & 0.0000 \\
B\&P test & & 1023.21 & 0.0000 \\
Hausman test & & 20.14 & 0.0012 \\
\hline
\end{tabular}

Considering the spatial correlation, we used LM test and Robust LM test to compare the Spatial Autoregressive Model (SAR) with the Spatial Error Model (SEM), as is shown in Table 6. It can be seen from the LM results that the LM statistics of both the SAR model and the SEM model are at the significance level of $5 \%$, rejecting the null hypothesis that there is no spatial lag term and spatial error term. The result indicates that the two models can be used to analyze the influencing factors of agricultural green development. From the perspective of robust LM test results, the SAR model failed to pass the significance test, indicating that the SEM model is better than the SAR model. 
Table 6. LM test results.

\begin{tabular}{lccc}
\hline \multicolumn{1}{c}{ Test } & Statistics & Df & $p$-Value \\
\hline Spatial error: & & & \\
$\quad$ Lagrange multiplier & 229.836 & 1 & 0.000 \\
$\quad$ Robust Lagrange multiplier & 213.301 & 1 & 0.000 \\
Spatial lag: & 17.272 & 1 & 0.000 \\
$\quad$ Lagrange multiplier & 0.736 & 1 & 0.391 \\
$\quad$ Robust Lagrange multiplier &
\end{tabular}

In order to make the estimation results more accurate, based on the fixed effect model estimation results of Spatial Durbin Model (SDM), we used Wald test and likelihood ratio (LR) test to determine whether the SDM model with fixed effect needs to be simplified to SAR model or SEM model. The test results are shown in Table 7, where the null hypothesis of test 1 is $\theta=0$, and the null hypothesis of test 2 is $\theta=-\rho \beta$. From the test results, we can see that the statistics of the two tests are both at the significance of $1 \%$ and reject the null hypothesis. The results mean that there may be bias when only using the SAR model or the SEM model to analyze the spatial spillover effect of influencing factors of agricultural green development, and the SDM model is the suitable spatial econometric model.

Table 7. Model comparison test results.

\begin{tabular}{ccc}
\hline & Chi2 (4) & Prob > Chi2 \\
\hline Test 1 & 21.85 & 0.0002 \\
Test 2 & 18.40 & 0.0010 \\
\hline
\end{tabular}

In this article, we listed the regression results of the fixed effect model under the SDM model, the SAR model, the SEM model, and the OLS model for comparative analysis, and the results are shown in Table 8. According to the results in Table 8, compared with the SAR model, the SEM model, and the OLS model, the SDM model considering spatial lag effect terms and spatial error effect terms has the best fitting effect, indicating that spatial geographical factors cannot be ignored when analyzing the influencing factors of agricultural green development level. After comparing the significance of each variable, the significance of spatial effect, and the Log-likelihood, it is found that the spatial effect of the three spatial econometric models is at the significance of $1 \%$. However, the independent variable coefficient of the SDM model is more significant, and the Log-likelihood value is the largest, which further confirms that the SDM model is the optimal estimation model.

In order to clarify the type of the selected model, we made a further test on the fixed effect model under the Spatial Durbin model, exploring the choice of spatial fixed effect model, time fixed effect model, or spatial and time double fixed effect model, as is shown in Table 9. According to the results in Table 9, although the fitting effect under the time fixed effect is lower than that under the spatial fixed effect, the coefficient of each variable of the estimated result under the time fixed effect is significant. Therefore, this article selected the time fixed effect model under the Spatial Durbin Model for analysis. 
Table 8. Model comparison estimation results.

\begin{tabular}{|c|c|c|c|c|}
\hline & SDM & SAR & SEM & OLS \\
\hline $\operatorname{lnurb}$ & $\begin{array}{l}0.2325^{* * *} \\
(0.0719)\end{array}$ & $\begin{array}{c}0.0407 \\
(0.0535)\end{array}$ & $\begin{array}{l}0.1093 * \\
(0.0602)\end{array}$ & $\begin{array}{c}0.0388 \\
(0.0574)\end{array}$ \\
\hline lnmech & $\begin{array}{l}0.0901^{* * *} \\
(0.0196)\end{array}$ & $\begin{array}{c}0.0803 * * * \\
(0.0157)\end{array}$ & $\begin{array}{c}0.0892^{* * *} \\
(0.0171)\end{array}$ & $\begin{array}{c}0.0853^{* * *} \\
(0.0168)\end{array}$ \\
\hline lnrnd & $\begin{array}{l}0.1925^{*} \\
(0.0111)\end{array}$ & $\begin{array}{l}0.0181 * * \\
(0.0087)\end{array}$ & $\begin{array}{l}0.0162 * \\
(0.0093)\end{array}$ & $\begin{array}{c}0.0263^{* * *} \\
(0.0090)\end{array}$ \\
\hline Inland & $\begin{array}{c}-0.2373^{* * *} \\
(0.0747)\end{array}$ & $\begin{array}{c}-0.1407^{* * *} \\
(0.0513)\end{array}$ & $\begin{array}{c}-0.1649 * * * \\
(0.0589)\end{array}$ & $\begin{array}{c}-0.1499 * * * \\
(0.0550)\end{array}$ \\
\hline$W \times \operatorname{lnurb}$ & $\begin{array}{c}-0.4328^{* * *} \\
(0.1002)\end{array}$ & & & \\
\hline$W \times \operatorname{lnmech}$ & $\begin{array}{l}-0.0333 \\
(0.0324)\end{array}$ & & & \\
\hline$W \times \ln r n d$ & $\begin{array}{l}0.0366^{* *} \\
(0.0144)\end{array}$ & & & \\
\hline$W \times \operatorname{lnland}$ & $\begin{array}{l}0.2180 * * \\
(0.1039)\end{array}$ & & & \\
\hline$\rho$ & $\begin{array}{l}0.2574^{* * *} \\
(0.0644)\end{array}$ & $\begin{array}{l}0.2252 * * * \\
(0.0633)\end{array}$ & & \\
\hline$\lambda$ & & & $\begin{array}{c}0.2706^{* * *} \\
(0.0676)\end{array}$ & \\
\hline sigma $^{2}$ & $\begin{array}{l}0.0018^{* * *} \\
(0.0001)\end{array}$ & $\begin{array}{l}0.0020 * * * \\
(0.0001)\end{array}$ & $\begin{array}{l}0.0019 * * * \\
(0.0001)\end{array}$ & \\
\hline $\mathrm{R}^{2}$ & 0.2920 & 0.2539 & 0.2540 & 0.2573 \\
\hline Log-likelihood & 639.8792 & 629.3011 & 630.7409 & \\
\hline
\end{tabular}

Table 9. Estimation of fixed effect types results.

\begin{tabular}{|c|c|c|c|}
\hline & Spatial Fixed Effect & Time Fixed Effect & Spatial and Time Fixed Effect \\
\hline \multirow{2}{*}{ lnurb } & $0.2325^{* * *}$ & $0.2051^{* * *}$ & $0.2597^{* * *}$ \\
\hline & $(0.0719)$ & $(0.0361)$ & $(0.0701)$ \\
\hline \multirow{2}{*}{ lnmech } & $0.0901^{* * *}$ & $0.1682 * * *$ & $0.0870^{* * *}$ \\
\hline & $(0.0196)$ & $(0.0145)$ & $(0.0188)$ \\
\hline \multirow{2}{*}{ lnrnd } & 0.1925 * & $0.0700^{* * *}$ & 0.0086 \\
\hline & $(0.0111)$ & $(0.0081)$ & $(0.0111)$ \\
\hline \multirow{2}{*}{ Inland } & $-0.2373^{* * *}$ & $-0.1652 * * *$ & $-0.2338^{* * *}$ \\
\hline & $(0.0747)$ & $(0.0146)$ & $(0.0718)$ \\
\hline \multirow{2}{*}{$W \times \operatorname{lnurb}$} & $-0.4328^{* * *}$ & $-0.2738^{* * *}$ & $-0.5617^{* * *}$ \\
\hline & $(0.1002)$ & $(0.0572)$ & $(0.1156)$ \\
\hline \multirow{2}{*}{$W \times \operatorname{lnmech}$} & -0.0333 & $-0.2203^{* * *}$ & -0.0159 \\
\hline & $(0.0324)$ & $(0.0286)$ & $(0.0369)$ \\
\hline \multirow{2}{*}{$W \times \ln r n d$} & $0.0366^{* *}$ & $0.0793^{* * *}$ & -0.0034 \\
\hline & $(0.0144)$ & $(0.0147)$ & $(0.0179)$ \\
\hline \multirow{2}{*}{$W \times \operatorname{lnland}$} & $0.2180 * *$ & $0.1218^{* * *}$ & 0.1269 \\
\hline & $(0.1039)$ & $(0.0270)$ & $(0.1119)$ \\
\hline \multirow[b]{2}{*}{$\rho$} & $0.2574^{* * *}$ & $0.2795^{* * *}$ & 0.0755 \\
\hline & $(0.0644)$ & $(0.0645)$ & $(0.0727)$ \\
\hline \multirow{2}{*}{ sigma $^{2}$} & $0.0018^{* * *}$ & $0.0076^{* * *}$ & $0.0017^{* * *}$ \\
\hline & $(0.0001)$ & $(0.0006)$ & $(0.0001)$ \\
\hline $\mathrm{R}^{2}$ & 0.2920 & 0.2292 & 0.0199 \\
\hline Log-likelihood & 639.8792 & 377.5491 & 659.0086 \\
\hline
\end{tabular}




\subsubsection{Results and Discussion}

Due to the vast territory of China, there are obvious differences in agricultural resource endowments and supporting policies in different provinces. Therefore, there are obvious regional differences in the factors that affecting the level of agricultural green development. In order to analyze the spatial characteristics and spatial spillover effect of the factors affecting the level of agricultural green development in different regions, China can be divided into three areas based on the geographical and administrative location, i.e., the eastern, central, and western areas, as is shown in Table 10 [48]. In this study, 31 provinces (municipalities, autonomous regions) were considered exclusive of Hong Kong, Macao, and Taiwan for the data absence.

Table 10. The regional classification in China.

\begin{tabular}{|c|c|}
\hline Regions & Provinces (Municipalities, Autonomous Regions) \\
\hline Eastern area & $\begin{array}{c}\text { Beijing, Tianjin, Hebei, Liaoning, Shanghai, Jiangsu, Zhejiang, Fujian, Shandong, } \\
\text { Guangdong, Hainan }\end{array}$ \\
\hline Central area & Shanxi, Jilin, Heilongjiang, Anhui, Jiangxi, Henan, Hubei, Hunan \\
\hline Western area & $\begin{array}{c}\text { Mongolia, Guangxi, Chongqing, Sichuan, Guizhou, Yunnan, Tibet, Shaanxi, } \\
\text { Gansu, Qinghai, Ningxia, Xinjiang }\end{array}$ \\
\hline
\end{tabular}

The article constructs the Spatial Durbin Model with time fixed effect on the influencing factors of agricultural green development in the nation, the eastern area, the central area, and the western area for analysis, and the estimated results are shown in Table 11.

Table 11. Estimation of the Spatial Durbin Model (SDM) model of influencing factors of AGD level.

\begin{tabular}{|c|c|c|c|c|}
\hline & Nation & Eastern & Central & Western \\
\hline lnurb & $\begin{array}{l}0.2051^{* * *} \\
(0.0361)\end{array}$ & $\begin{array}{c}-0.4919^{* * *} \\
(0.1299)\end{array}$ & $\begin{array}{c}-0.3015^{* * *} \\
(0.1044)\end{array}$ & $\begin{array}{c}0.1775^{* * *} \\
(0.0374)\end{array}$ \\
\hline lnmech & $\begin{array}{l}0.1682 * * * \\
(0.0145)\end{array}$ & $\begin{array}{l}0.0800 * * \\
(0.0359)\end{array}$ & $\begin{array}{c}0.0315 \\
(0.0266)\end{array}$ & $\begin{array}{c}0.1821 * * * \\
(0.0319)\end{array}$ \\
\hline lnrnd & $\begin{array}{l}0.0700 * * * \\
(0.0081)\end{array}$ & $\begin{array}{c}0.1225^{* * *} \\
(0.0157)\end{array}$ & $\begin{array}{c}0.0249 \\
(0.0164)\end{array}$ & $\begin{array}{c}0.1447^{* * *} \\
(0.0152)\end{array}$ \\
\hline Inland & $\begin{array}{c}-0.1652 * * * \\
(0.0146)\end{array}$ & $\begin{array}{c}-0.1719^{* * *} \\
(0.0447)\end{array}$ & $\begin{array}{c}-0.2492^{* * *} \\
(0.0282)\end{array}$ & $\begin{array}{c}-0.2242^{* * * *} \\
(0.0247)\end{array}$ \\
\hline$W \times \operatorname{lnurb}$ & $\begin{array}{c}-0.2738^{* * *} \\
(0.0572)\end{array}$ & $\begin{array}{l}-0.0964 \\
(0.2098)\end{array}$ & $\begin{array}{l}-0.2603 \\
(0.1980)\end{array}$ & $\begin{array}{c}-0.3382^{* * *} \\
(0.0592)\end{array}$ \\
\hline$W \times$ lnmech & $\begin{array}{c}-0.2203^{* * *} \\
(0.0286)\end{array}$ & $\begin{array}{l}-0.1627^{* *} \\
(0.0658)\end{array}$ & $\begin{array}{c}-0.2768^{* * *} \\
(0.0522)\end{array}$ & $\begin{array}{l}-0.0309 \\
(0.0756)\end{array}$ \\
\hline$W \times \ln r n d$ & $\begin{array}{c}0.0793^{* * *} \\
(0.0147)\end{array}$ & $\begin{array}{c}0.0315 \\
(0.0244)\end{array}$ & $\begin{array}{c}-0.0459 * * \\
(0.0216)\end{array}$ & $\begin{array}{c}0.0439 \\
(0.0438)\end{array}$ \\
\hline$W \times \operatorname{lnland}$ & $\begin{array}{c}0.1218 * * * \\
(0.0270)\end{array}$ & $\begin{array}{c}0.1223 \\
(0.0991)\end{array}$ & $\begin{array}{c}-0.0931 \text { ** } \\
(0.0375)\end{array}$ & $\begin{array}{c}0.0316 \\
(0.0570)\end{array}$ \\
\hline$\rho$ & $\begin{array}{l}0.2795^{* * *} \\
(0.0645)\end{array}$ & $\begin{array}{c}0.1203 \\
(0.0968)\end{array}$ & $\begin{array}{l}-0.1041 \\
(0.1007)\end{array}$ & $\begin{array}{l}-0.0661 \\
(0.1322)\end{array}$ \\
\hline sigma $^{2}$ & $\begin{array}{c}0.0076^{* * *} \\
(0.0006)\end{array}$ & $\begin{array}{c}0.0062 * * * \\
(0.0008)\end{array}$ & $\begin{array}{c}0.0021 * * * \\
(0.0003)\end{array}$ & $\begin{array}{c}0.0033^{* * *} \\
(0.0004)\end{array}$ \\
\hline $\mathrm{R}^{2}$ & 0.2292 & 0.1181 & 0.3336 & 0.1681 \\
\hline Log-likelihood & 377.5491 & 148.1407 & 160.2003 & 207.1059 \\
\hline
\end{tabular}

Note: Standard errors in parentheses ${ }^{* *} p<0.05,{ }^{* * *} p<0.01$.

From the national perspective, the four influencing factors of urbanization level, agricultural mechanization level, scientific and technological R\&D investment, and arable land area have significant impacts on the level of agricultural green development in China at the significance level of $1 \%$. Among the four factors, urbanization level, agricultural mechanization level, and scientific and technological $R \& D$ investment have a positive impact on the level of agricultural green development, while arable 
land area has a negative impact on the level of agricultural green development. Meanwhile, the factors in the adjacent regions have a significant impact on the provincial agricultural green development level. Among the four factors, the urbanization level and agricultural mechanization level in the adjacent provinces have a significant negative impact on the provincial agricultural green development level, while the scientific and technological R\&D investment and arable land area in the adjacent provinces have a significant positive impact on the provincial agricultural green development level.

From the regional level, the impact of various factors on the level of agricultural green development in different regions is different, and the impact direction is also different. Therefore, we adopted the horizontal comparison method to analyze each variable in the eastern, central, and western areas to illustrate the spatial heterogeneity.

Considering the impact of the variable "lnurb" on the level of agricultural green development, the urbanization level has a significant impact on the green development of agriculture in the eastern, central, and western areas at a significance level of $1 \%$, but there are differences in the impact direction. The coefficient of "lnurb" is significantly negative in the eastern and central areas and is significantly positive in the western area. The eastern and western areas have superior geographical location and are economically developed. The improvement of urbanization level releases the surplus labor force in rural areas to engage in the secondary and tertiary industries, which increases the emission of environmental pollution, thus restraining the green development of agriculture. The urbanization level in the western area is in the initial stage, and the improvement of urbanization level gathers some social resources, which is conducive to accelerating the promotion of the green development of agriculture.

Considering the impact of the variable "lnmech" on the level of agricultural green development, the impact of agricultural mechanization level on the green development of agriculture in the eastern and western areas is positive at the significance level of $5 \%$ and $1 \%$, respectively. In the process of agricultural production, agricultural machinery can improve agricultural production efficiency, improve land productivity, save labor, and promote the green development of agriculture.

Regarding the impact of the variable "Inrnd" on the level of agricultural green development, the impact of scientific and technological $R \& D$ investment on the green development of agriculture in the eastern and western areas is positive at the significance level of $1 \%$. Investment in scientific and technological research and development can effectively promote technological progress, and technological progress provides guarantee for the entire process of agricultural production, as well as improving the agricultural production efficiency in the meantime, which can promote the green development of agriculture.

With regards to the impact of the variable "Inland" on the level of agricultural green development, the impact of arable land area on the green development of agriculture in the eastern, central, and western areas is negative at the significance level of $1 \%$. In recent years, with the acceleration of industrialization and urbanization, the arable land area has a trend of continuous decrease, but the increase of the utilization rate and output rate of arable land has played a significant positive role in the green development of agriculture.

Considering the impact of the variable " $W \times \operatorname{lnurb}$ " on the level of agricultural green development, the urbanization level in adjacent provinces is significantly negative in the western area at a significance level of $1 \%$, indicating that the regional spillover effect of urbanization on agricultural green development is negative. The improvement of urbanization level in adjacent provinces has a restraining effect on the local green development of agriculture for the western area. The possible reason is that the development of urbanization in the western area can attract agricultural surplus labor in adjacent provinces, which has led to a decline in the level of agricultural development in the local area.

Concerning the impact of the variable " $W \times$ lnmech" on the level of agricultural green development, the agricultural mechanization level in adjacent provinces is significantly negative in the eastern and central areas at a significance level of $5 \%$ and $1 \%$, respectively, indicating that the regional spillover effect 
of agricultural mechanization level on agricultural green development is negative. The improvement of agricultural mechanization level in adjacent provinces has a restraining effect on the local green development of agriculture for the eastern and central area.

Regarding the impact of the variable " $W \times \ln r n d$ " on the level of agricultural green development, the scientific and technological R\&D investment in adjacent provinces is significantly negative in the central area at a significance level of 5\%, indicating that the regional spillover effect of scientific and technological R\&D investment on agricultural green development is negative. The increase of scientific and technological R\&D investment in adjacent provinces has a restraining effect on the local green development of agriculture for the central area.

Finally, with regards to the impact of the variable " $W \times \operatorname{lnland}$ " on the level of agricultural green development, the arable land area in adjacent provinces is significantly negative in the central area at a significance level of $5 \%$, indicating that the regional spillover effect of arable land area on agricultural green development is negative. The increase of arable land area in adjacent provinces has a restraining effect on the local green development of agriculture for the central area.

\section{Conclusions and Policy Implications}

\subsection{Conclusions}

Firstly, we evaluated the level of agricultural green development in China from 2007 to 2018, and the results showed that the level of agricultural green development in China presented a fluctuating upward trend, and there are differences among provinces. On the whole, the level of agricultural green development in the three major regions presented the characteristics of Eastern $>$ Central $>$ Western.

Secondly, we explored the spatial relationship of the level of agricultural green development among provinces in China. The results showed that China's provincial agricultural green development (AGD) level has an obvious positive autocorrelation in spatial distribution, showing the significant characteristics of spatial agglomeration in space

Finally, the Spatial Durbin Model was used to analyze the influencing factors of agricultural green development in China. The results showed that, from the national perspective, the urbanization level, agricultural mechanization level, scientific and technological R\&D investment, and the arable land area had significant impact on the level of agricultural green development in the local and adjacent areas. From the regional perspective, in the eastern area, the four factors had a significant impact on the local green development agriculture, and the agricultural mechanization level in adjacent areas had a negative significant impact on the local green development of agriculture. In the central area, the urbanization level and arable land area had a significant impact on the local green development of agriculture, and the mechanization level, scientific and technological R\&D investment, and arable land area in adjacent areas had a negative significant impact on the local green development of agriculture. In the western area, the four factors had a significant impact on the local green development of agriculture, and the urbanization level in adjacent areas had a significant negative impact on the local green development of agriculture.

\subsection{Policy Implications}

On the basis of the above results, several relevant policy implications can be derived, as follows:

First, agricultural green development is a systematic and complex issue. Therefore, China should introduce an authoritative and scientific agricultural green development level evaluation system and strengthen the monitoring of various data such as agricultural resources and the environment. In this way, China can make dynamic evaluation of agricultural green development in various provinces, which is helpful for the timely issue policies to promote the green transformation of agriculture.

Second, China should accelerate the integration of urban and rural areas, promote the integrated development of the three major industries, and optimize the structure; in addition, paying more 
attention to the preference for agriculture, so as to realize green efficiency in agricultural production and stable growth of farmers' income.

Third, China should increase the scientific and technological R\&D investment in the whole process of agricultural production, including agricultural machinery, agricultural intelligent equipment, and water-saving and energy-saving equipment, etc.

Fourth, the stability of the amount of arable land resources is the most basic element to ensure national food security. It is necessary to establish a strict protection system to protect the red line of 1.8 billion $\mathrm{mu}$ of arable land. While ensuring the quantity of arable land resources, the quality of soil should also be improved to ensure the stability and quality of arable land.

\section{Limitations and Future Work}

There are some limitations in this article. First, this study focuses on the estimation of the agricultural green development and its influencing factors in China based on the static Spatial Durbin Model, but the long-term dynamic association may be different or more complex. Therefore, the dynamic Spatial Durbin Model with time series is also worth discussing. Second, the spatial heterogeneity of China's agricultural green development is only divided into three regions of the eastern, the central, and the west, therefore there may be a spatial spillover effect bias problem in this article. If the geographical regions of China are divided into more regions, the influence of various factors on different regions may be changed.

In the future research, additional aspects should be considered. First, we will incorporate the time series factor into the model and discuss the time and spatial heterogeneity of agricultural green development in China with the dynamic panel data under the consideration of time and space. Second, we will subdivide the geographical regions of China from three major regions into six geographical regions to make the research conclusions more accurate.

Author Contributions: Conceptualization, H.G. and C.P.; methodology, H.G. and S.X.; software, H.G. and S.X.; validation, H.G. and S.X.; formal analysis, H.G.; resources, H.G.; data curation, C.P.; writing-original draft preparation, H.G.; writing-review and editing, S.X. and C.P.; visualization, H.G.; supervision, C.P.; project administration, H.G.; funding acquisition, H.G. All authors have read and agreed to the published version of the manuscript.

Funding: This research was funded by Social Science Fund Project of Jilin Province, China, grant No.2017B032; MOE (Ministry of Education in China) Project of Humanities and Social Sciences, grant/award No.18YJC630128; Social Science Fund Project of Jilin Province, China, grant No.2018BS33; and Social Science Fund Project of "the 13th Five-Year" of Education Department of Jilin Province, China, grant No.JJKH20190736SK.

Conflicts of Interest: The authors declare no conflict of interest.

\section{References}

1. Kanter, D.R.; Musumba, M.; Wood, S.L.R.; Palm, C.; Antle, J.; Balvanera, P.; Dale, V.H.; Havlik, P.; Kline, K.L.; Scholes, R.J.; et al. Evaluating agricultural trade-offs in the age of sustainable development. Agric. Syst. 2018, 163, 73-88. [CrossRef]

2. Ma, L.; Zhang, W.F.; Ma, W.Q.; Velthof, G.L.; Oenema, O.; Zhang, F.S. An Analysis of Developments and Challenges in Nutrient Management in China. J. Environ. Qual. 2013, 42, 951-961. [CrossRef] [PubMed]

3. Yang, H.S. Resource management, soil fertility and sustainable crop production: Experiences of China. Agric. Ecosyst. Environ. 2006, 116, 27-33. [CrossRef]

4. Liu, X.B.; Zhang, X.Y.; Herbert, S.J. Feeding China's growing needs for grain. Nature 2010, 465, 420. [CrossRef] [PubMed]

5. Guo, J.H.; Liu, X.J.; Zhang, Y.; Shen, J.L.; Han, W.X.; Zhang, W.F.; Christie, P.; Goulding, K.W.T.; Vitousek, P.M.; Zhang, F.S. Significant Acidification in Major Chinese Croplands. Science 2010, 327, 1008-1010. [CrossRef] [PubMed]

6. Liu, X.J.; Zhang, Y.; Han, W.X.; Tang, A.H.; Shen, J.L.; Cui, Z.L.; Vitousek, P.; Erisman, J.W.; Goulding, K.; Christie, P.; et al. Enhanced nitrogen deposition over China. Nature 2013, 494, 459-462. [CrossRef] [PubMed] 
7. Stoll-Kleemann, S.; Schmidt, U.J. Reducing meat consumption in developed and transition countries to counter climate change and biodiversity loss: A review of influence factors. Reg. Environ. Chang. 2017, 17, 1261-1277. [CrossRef]

8. Firbank, L.G. Towards the sustainable intensification of agriculture-a systems approach to policy formulation. Front. Agric. Sci. Eng. 2020, 7, 81-89. [CrossRef]

9. Schmidt-Traub, G. The urgency of Agriculture Green Development. Front. Agric. Sci. Eng. 2020, 7, 108-109. [CrossRef]

10. Shen, J.B.; Zhu, Q.C.; Jiao, X.Q.; Ying, H.; Wang, H.L.; Wen, X.; Xu, W.; Li, T.Y.; Cong, W.F.; Liu, X.J.; et al. Agriculture Green Development: A model for China and the world. Front. Agric. Sci Eng. 2020, 7, 5-13. [CrossRef]

11. Nambiar, K.K.M.; Gupta, A.P.; Fu, Q.L.; Li, S. Biophysical, chemical and socio-economic indicators for assessing agricultural sustainability in the Chinese coastal zone. Agric. Ecosyst. Environ. 2001, 87, $209-214$. [CrossRef]

12. Quintero-Angel, M.; Gonzalez-Acevedo, A. Tendencies and challenges for the assessment of agricultural sustainability. Agric. Ecosyst. Environ. 2018, 254, 273-281. [CrossRef]

13. Rigby, D.; Caceres, D. Organic farming and the sustainability of agricultural systems. Agric. Syst. 2001, 68, 21-40. [CrossRef]

14. Taylor, D.; Mohamed, Z.; Shamsudin, M.N.; Mohayidin, M.G.; Chiew, E. Creating a farmer sustainability index: A Malaysian case study. Am. J. Altern. Agric. 1993, 8, 175-184. [CrossRef]

15. Van Calker, K.J.; Berentsen, P.B.M.; Romero, C.; Giesen, G.W.J.; Huirne, R.B.M. Development and application of a multi-attribute sustainability function for Dutch dairy farming systems. Ecol. Econ. 2006, 57, 640-658. [CrossRef]

16. Zhen, L.; Routray, J.K. Operational indicators for measuring agricultural sustainability in developing countries. Environ. Manag. 2003, 32, 34-46. [CrossRef]

17. Wei, Q.; Zhang, B.; Jin, S. A Study on Construction and Regional Comparison of Agricultural Green Development Index in China. Issues Agric. Econ. 2018, 11, 11-20.

18. Gong, Q.; Li, X. Construction and Measurement of Agricultural Green Development Index: 2005-2018. Reform 2020, 1, 133-145.

19. Gong, X.; Luo, R. The Evaluation of Agricultural Green Development Ability in Western Regions from the Perspective of Precise Poverty Alleviation. Ecol. Econ. 2018, 34, 128-132.

20. Jia, Y.; Zhao, B.; He, Z.; Zhang, Z.; Zhang, R. Research on evaluation and direction of the green development of agriculture in Henan province. J. Henan Agric. Univ. 2019, 53, 823-830.

21. Jin, S. Evaluation of provincial agricultural green development level and regional differences in China. Seeker 2019, 89-95. [CrossRef]

22. Zhao, H.; Yu, F. Evaluation of Agricultural Green Development Level in Main Grain Producing Areas based on Entropy Method. Reform 2019, 11, 136-146.

23. Zhou, L. Research on the Green Development of Tibetan Agriculture under the Background of Rural Revitalization. Northwestern J. Ethnol. 2019, 116-127. [CrossRef]

24. Carson, H.L. Silent Spring. Coll. Univ. 1963, 38, 294-296.

25. Davies, W.J.; Shen, J.B. Reducing the environmental footprint of food and farming with Agriculture Green Development. Front. Agric. Sci. Eng. 2020, 7, 1-4. [CrossRef]

26. Godfray, H.C.J.; Beddington, J.R.; Crute, I.R.; Haddad, L.; Lawrence, D.; Muir, J.F.; Pretty, J.; Robinson, S.; Thomas, S.M.; Toulmin, C. Food Security: The Challenge of Feeding 9 Billion People. Science 2010, 327, 812-818. [CrossRef]

27. Tu, Z.; Gan, T. Research on the Regional Difference and Dynamic Mechanism of Agricultural Green Development in China. Wuhan Univ. J. (Philos. Soc. Sci.) 2019, 72, 165-178.

28. Koohafkan, P.; Altieri, M.A.; Gimenez, E.H. Green Agriculture: Foundations for biodiverse, resilient and productive agricultural systems. Int. J. Agric. Sustain. 2012, 10, 61-75. [CrossRef]

29. Leimona, B.; Amaruzaman, S.; Arifin, B.; Yasmin, F.; Hasan, F.; Agusta, H.; Sprang, P.; Jaffee, S.; Frias, J. Indonesia's 'Green Agriculture' Strategies and Policies: Closing the Gap Between Aspirations and Application. In Bogor, Indonesia: World Agroforestry Centre and World Bank; World Agroforestry Centre: Nairobi, Kenya, 2015.

30. Yu, J.L.; Wu, J. The Sustainability of Agricultural Development in China: The Agriculture-Environment Nexus. Sustain-Basel 2018, 10, 1776. [CrossRef] 
31. Jin, S.Q.; Ma, H.Y.; Huang, J.K.; Hu, R.F.; Rozelle, S. Productivity, efficiency and technical change: Measuring the performance of China's transforming agriculture. J. Prod. Anal. 2010, 33, 191-207. [CrossRef]

32. Yu, X.R. Promoting Agriculture Green Development to realize the great rejuvenation of the Chinese nation. Front. Agric. Sci. Eng. 2020, 7, 112-113.

33. Zhang, F.S.; Dong, W.C.; Li, J.Q. Creating a new university-education system to promote Agriculture Green Development. Front. Agric. Sci. Eng. 2020, 7, 114-116. [CrossRef]

34. Zhang, J.J.; Cui, S.L.; Ma, L.; Meng, F.L.; Song, C.Y.; Li, Y.M.; Ma, W.Q. Construction of a green development index system for agriculture in China and examples. Chin. J. Eco-Agric. 2020, 28, 1113-1126.

35. Jiang, Y. Level of Development of Hunan Agricultural Green Measure and Development Path Selection Research; Hunan Agricultural University: Changsha, China, 2018.

36. Ren, H.J.; Liu, Y.F.; Ding, S.X. Research on the Measurement of Agricultural Green Development Level in Qinghai Province. IOP Conf. Ser. Earth Environ. 2019, 267. [CrossRef]

37. Cheng, Y. Study on Evaluation of Agricultural Green Development in Shanxi Province; Shanxi University of Finance and Economics: Taiyuan, China, 2019.

38. Yang, X. Study on the Measurement and Promotion Path of Agricultural Green Development Level in China; Hebei University of Economics and Business: Shijiazhuang, China, 2019.

39. Guo, M. Reasearch of Agricultural Green Development and A Preliminary study on the Evaluation System; Beijing Forestry University: Beijing, China, 2011.

40. Jing, P.; Zhao, W.; Zheng, Q.; Zhang, D. Study On Dynamic Prediction and Path of Green Development Level of Agriculture in Anhui Province. Chin. J. Agric. Resour. Regional. Plan. 2018, 39, 51-56.

41. Zhang, N.; Zhang, L.; Zhao, H.; Han, Y.; Duan, Y. Construction and Application of Evaluation Index System for Agricultural Green Development. Ecol. Econ. 2018, 34, 21-24+46.

42. Lin, X.; Wang, D.; Ren, W.; Liu, Y. Research on the mechanism of urbanization to economic increase in China. Geogr. Res. 2013, 32, 691-700.

43. Wang, B.; Tang, W.; Wu, Y.; Zhang, N. Does Urbanization Increase China's Green Development Efficiency? Econ. Rev. 2014, 4, 38-49.

44. Xue, L.; Shen, Y.; Xu, C. A Research on Spillover Effects of Agricultural Agglomeration on Agricultural Green Development Efficiency. Econ. Surv. 2020, 37, 45-53.

45. Yang, L.; Sun, Z. The Development of Western New-type Urbanization Level Evaluation Based on Entropy Method. Econ. Probl. 2015, 115-119. [CrossRef]

46. Moran, P.A.P. The Interpretation of Statistical Maps. J. R. Stat. Soc. Ser. B Stat. Methodol. 1948, 37, $243-251$. [CrossRef]

47. Anselin, L. Local Indicators of Spatial Association-Lisa. Geogr. Anal. 1995, 27, 93-115. [CrossRef]

48. Xu, S.; Li, Y.; Tao, Y.; Wang, Y.; Li, Y. Regional Differences in the Spatial Characteristics and Dynamic Convergence of Environmental Efficiency in China. Sustain.-Basel 2020, 12, 7423. [CrossRef]

Publisher's Note: MDPI stays neutral with regard to jurisdictional claims in published maps and institutional affiliations.

(C) 2020 by the authors. Licensee MDPI, Basel, Switzerland. This article is an open access article distributed under the terms and conditions of the Creative Commons Attribution (CC BY) license (http://creativecommons.org/licenses/by/4.0/). 